\title{
INVESTIGATING WATER STORAGE CHANGES IN IRAN USING GRACE AND CHIRPS DATA IN THE GOOGLE EARTH ENGINE SYSTEM
}

\author{
S. Shami ${ }^{1 *}$, Z. Ghorbani ${ }^{2}$ \\ ${ }^{1}$ Faculty of Geodesy and Geomatics Engineering, Department of Geodesy, K. N. Toosi University of Technology, Tehran, Iran - \\ siavashshami@email.kntu.ac.ir \\ ${ }^{2}$ Faculty of Geodesy and Geomatics Engineering, Department of Geodesy, University of Zanjan (ZNU), Zanjan, Iran - \\ zahra.gh@znu.ac.ir
}

Commission VI, WG VI/4

KEYWORDS: Water Storage, GRACE, CHIRPS, Google Earth Engine, Iran

\begin{abstract}
:
Water storage in regions with the weather hot and arid or semi-arid such as Iran have many uses. Including these water storage, can be referred to groundwater. Groundwater is one of the sources of sweet waters in the world, and one of the factors is economical and social development. Hence, monitoring its changes in water resources management is of great importance. On the other hand, precipitation is one of the factors directly affecting the water storage level and groundwater level changes. In this study, water storage changes with GRACE satellite data and total annual precipitation with CHIRPS data in the Google Earth Engine system investigated for Iran during 2003-2017. The results obtained from the GRACE satellite data indicate over $10 \mathrm{~cm}$ reducing of the water storage levels in Iran during the period between 2008 to 2017. Also, the chart obtained from the CHIRPS data for the total annual precipitation shows that the amount of rainfall since 2008 has decreased in this region.
\end{abstract}

\section{INTRODUCTION}

Accurate monitoring and appropriate water storage changes in spatial and temporal dimensions for water resources management in countries with the weather arid and semi-arid such as Iran would be useful (Joodaki, 2014). Including necessary water storage, can be referred to as groundwater. Because groundwater is one of the factors of economic and social development and is one of the different sources of sweet waters in the world. The main factor in the formation of groundwater is of the earth's gravity and the penetration feature of water into the ground. As a result, a part of the surface water and rainfalls enter the underneath layers of the earth (Wahr et al., 2004a). In this way, the parameter that directly affects water storage, and the groundwater level changes are precipitation. The Climate Hazards Group Infrared Precipitation with Station data (CHIRPS) is a rainfall dataset which incorporates $0.05^{\circ}$ resolution satellite imagery with in-situ station data to create gridded rainfall time series for trend analysis and seasonal drought monitoring. Also, CHIRPS uses an approach to smart interpolation techniques and high resolution $\left(0.05^{\circ}\right)$, long period of record rainfall estimates based on infrared Cold Cloud Duration (CCD) observations (Funk et al., 2015a). The study of the changes in water storage and groundwater level with traditional methods is difficult due to the deficiency of hydrological data and large dimensions of the area (Joodaki, 2014b). Satellite observation with the ability to receive information with a spatial and temporal resolution of a wide area of land allows for monitoring and investigating the in groundwater level and water storage changes using remote sensing technology (Swenson and Wahr 200). Among satellites of remote sensing, GRACE satellites are very sensitive to water level changes, and by providing an estimate of the earth's gravity field, the relationship between water level changes and monthly changes earth's gravity field is established (Swenson et al., 2006a; Voss et al., 2013a). Changing the local gravity field influences the distance of the two satellites each other and can be achieved earth's gravity changes by measuring the distance between the two satellites (Swenson and Wahr, 2002a).In this way, monthly GRACE satellite data can be used to measure the water storage (groundwater, soil moisture, surface water, and snow). Among the factors affecting the level of water storage, groundwater has the most critical and most influence on the level of water reserves.

In the field of investigating and monitoring groundwater levels and water storage with remote sensing technology and GRACE satellite, Various studies have done in the past, including the can mention the following studies in recent years. In 2014, Joodaki et al. examined the human contribution in decline groundwater storage in the Middle East. In this study, which used from the 2002-2010 data, it became known that the groundwater levels are declining in some regions in the Middle East, particularly in the countries of Iraq and Iran. They also predicted that more than half of the decline in groundwater in Iran was due to human contribution (Joodaki et al., 2014a). In the same year, Petra Doll et al. examined the groundwater depletion on a global scale by integrating a hydrological model with GRACE satellite data (Doell et al., 2014a). In 2016, Chen et al. Discussed the status of groundwater storage in different parts of the earth planet, as well as the advantages of GRACE satellite against ground observations and the deficiencies of this satellite in estimating local-scale groundwater level changes (Chen et al., 2016a). In this research, the country of Iran selected and using the Google Earth Engine online system, the water storage changes by GRACE satellite data and annual precipitation in the region reviewed with CHIRPS data.

\footnotetext{
*corresponding author
} 


\section{THE STUDY AREA AND DATA USED}

\subsection{The study area}

Iran located in the Middle East region and geographic location 44 degrees 5 minutes at 63 degrees 18 minutes east longitude and 25 degrees 3 minutes at 39 degrees and 47 minutes north latitude. It is neighbouring with Armenia, Azerbaijan, and Turkmenistan in the north, Afghanistan, and Pakistan in the east, and Iraq and Turkey in the west. The country has an area equal to 1648198 square kilometres, which are $0.7 \%$ of that water. Also, in terms of climatic, the component countries semiarid (I.R.OF IRAN Meteorological Organization).

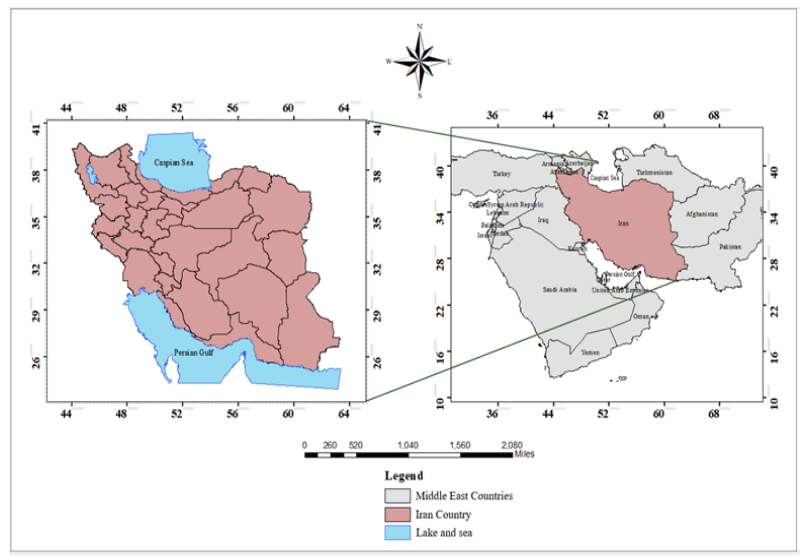

Figure 1. Location of the study area

\subsection{Data used}

In this study, 151 monthly data from GRACE satellite used between 2003 to 2017. Existing data expresses water storage (groundwater, soil moisture, surface water, and snow) in centimetre unit. These data produced by CSR (U. Texas / Center for Space Research), GFZ (Geo Forschungs Zentrum Potsdam), JPL (NASA Jet Propulsion Laboratory) research institutions. Since each of the institutions independently produces data, the output of each one can vary, so information from each of the three centres used. Information and the ability to estimate the minimum and maximum amounts of groundwater level changes for each of the data produced by the above institutions are as follows (Banerjee and Kumar, 2018; Landerer and Swenson, 2012a; Swenson and Wahr, 2006a).

\begin{tabular}{|c|c|c|c|c|}
\hline Name & Units & Min & Max & Resolution \\
\hline $\begin{array}{c}\text { lwe_thickness } \\
\text { _csr }\end{array}$ & centimeter & -139.2 & 74.88 & arc degree 1 \\
\hline $\begin{array}{c}\text { lwe_thickness } \\
\text { gfz }\end{array}$ & centimeter & -145.4 & 70.19 & arc degree 1 \\
\hline $\begin{array}{c}\text { lwe_thickness } \\
\text { _pl }\end{array}$ & centimeter & -137.9 & 71.86 & arc degree 1 \\
\hline
\end{tabular}

Table 1. Information on data produced by CSR, GFZ, and JPL (Google Earth Engine)

In addition to GRACE satellite data, from the CHIRPS data (version 2.0) was used to calculate the total annual precipitation during 2003-2017. CHIRPS incorporates station data in a twophase process, producing two unique products. In the first phase, which yields a preliminary rainfall product with 2-day latency and uses two station sources, GTS and Mexico. In the second phase, which yields a final product with a $\sim$ three-week latency and takes advantage of several other stations sources. CHIRPS providing blended gauge-satellite precipitation estimates that cover most global land regions and have relatively low latency, high resolution, low bias, and a long period of record. This dataset can be used related to land surface models to make useful mid-season drought forecasts or to analyse shifts in decadal precipitation in sparse data regions that depend on convective rainfall. CHIRPS data are available for several time steps, spatial domains, and formats including GeoTiff from 1981 to present (Funk et al., 2015a). The following table shows the data information used by CHIRPS.

\begin{tabular}{|c|c|c|c|c|}
\hline Name & Units & Min & Max & Resolution \\
\hline precipitation & $\mathrm{mm} /$ pentad & 0 & 1072.43 & $\begin{array}{c}\text { arc } 0.05 \\
\text { degrees }\end{array}$ \\
\hline
\end{tabular}

Table 2. Information on data produced by CHIRPS

\section{GRACE DATA AND CHIRPS DATA PROCESSING USING THE GOOGLE EARTH ENGINE SYSTEM}

In this study, has been used to processing GRACE satellite data and CHIRPS data from the Google Earth Engine system. The advantage of this system is no need to load data, and the data is ready for use in this system, and can they be processed only by calling data. Also, there is no need to perform geometric and radiometric corrections on the data. Additionally, in cases where the volume of data is high, there is no need for a robust processor system, and the system will call and process all existing data in less than a few minutes. All commands and programming codes are available in the system ready for processing ( Google Earth Engine).

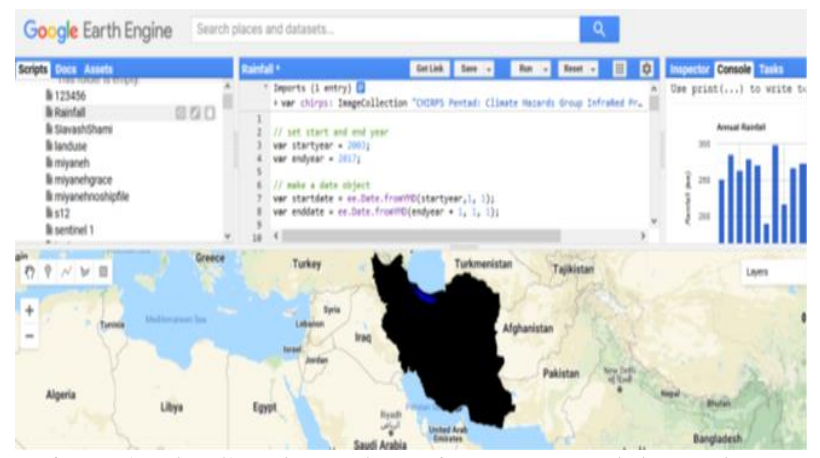

Figure 2. The Google Earth Engine system and the study area

\subsection{Results of water storage changes with GRACE data}

The monthly water level changes calculated with the following relation:

$$
\begin{gathered}
E W H(\varphi, \lambda)=\frac{a \rho_{\text {ave }}}{3 \rho_{w}} \sum_{l=0}^{\infty} \sum_{m=0}^{l} \frac{2 l+1}{1+k_{l}} \\
\widetilde{P}_{l m}(\sin \varphi)\left[\Delta C_{l m} \cos (m \lambda)+\Delta S_{l m} \sin (m \lambda)\right]
\end{gathered}
$$

where $\quad \rho_{\text {ave }}=5517^{\mathrm{kg}} / \mathrm{m}^{3}$ the average earth density $\rho_{w}=1000 \mathrm{~kg} / \mathrm{m}^{3}$ water densities

$a=\begin{array}{lll}6 & 3 & 7 \text { the radius of the earth }\end{array}$

$k_{l}=$ love the number of degrees $l$

$\tilde{P}_{l m}=$ Legendre's normalised functions

$\Delta S_{l m}, \Delta \mathrm{C}_{l m}=$ monthly variation of spherical harmonic coefficients

In order to estimate the water level changes equivalent to the geopotential models monthly coefficients difference, is 
calculated the total average of the models and estimated by putting in the above equation. One of the biggest problems with monthly GRACE data is the presence of noise in harmonic coefficients that increases with increasing degree and order. The filter is used to reduce the degree and high-order coefficients. The average water storage level changes for Iran using data produced by CSR, GFZ, and JPL institutions after processing with the Google Earth Engine online system are as following:

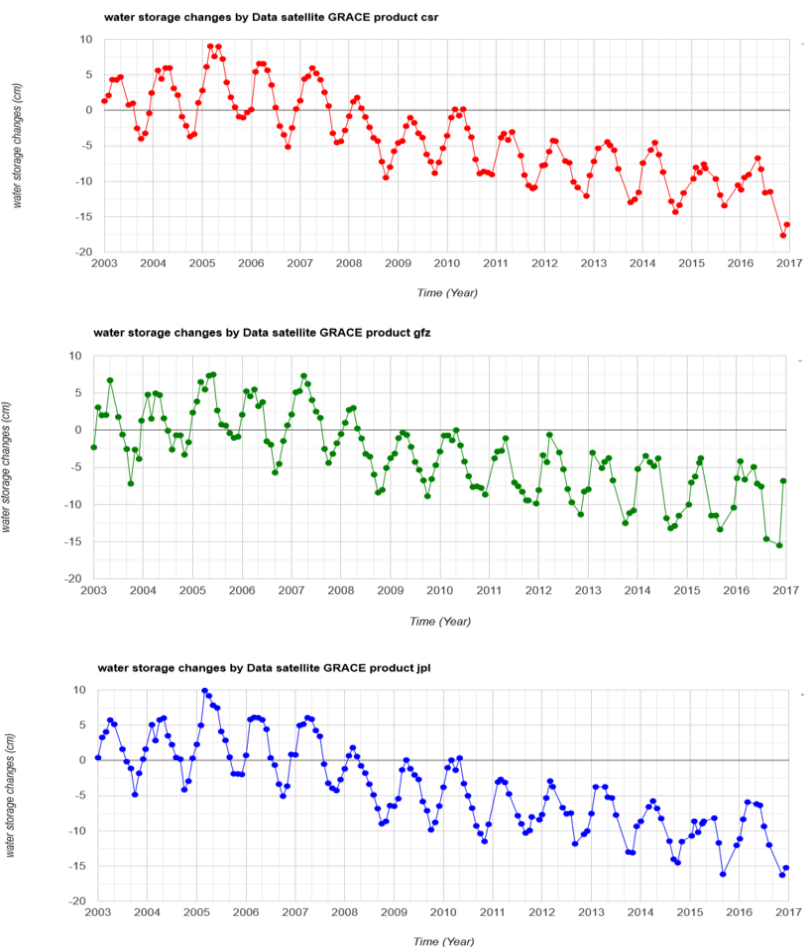

Figure 3. The average water storage level changes $(\mathrm{cm})$ for Iran with GRACE satellite and the Google Earth Engine system using the CSR, GFZ, and JPL data during the studies period 2003-2017

Due to the production of data by the three different institutions, the results are slightly different together. Therefore, the results compared with each other. As can be seen, the results show that reducing trend the average water storage level changes for Iran starting in 2008 and continues in the years to come.

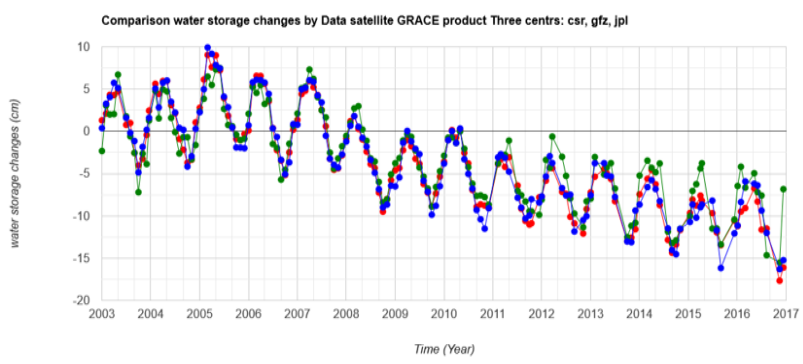

Figure 4. Comparison of water storage level changes $(\mathrm{cm})$ in Iran with the results of CSR, GFZ, and JPL data during 20032017

\subsection{Results of total annual precipitation data with CHIRPS} data

One of the factors that directly affect the water storage levels changes is precipitation. Because of the water storage levels changes with decreasing or increasing total annual precipitation.
In this study, using the of CHIRPS data, the total annual precipitation was calculated for Iran during 2003-2017.

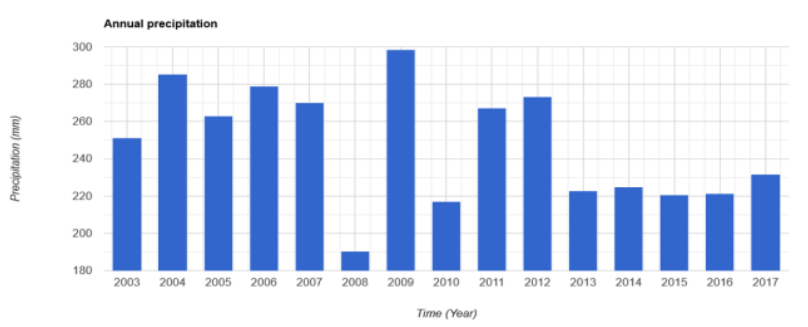

Figure 5. The chart, total annual precipitation $(\mathrm{mm})$ in Iran from 2003 to 2017

According to the results obtained from the total annual precipitation chart for Iran, it determined that the process of reducing rainfall in this country starting in 2008 and continued in the years to come.

\section{CONCLUSION}

The results of the GRACE satellite on water storage changes indicate that water storage over $10 \mathrm{~cm}$ during 2008-2017 reduced in Iran. On the other hand, the input of water storage is due to rainfall, so increasing, or decreasing rainfall has a direct effect on water storage level changes. Therefore, the total annual precipitation in Iran between 2003 and 2017 investigated with CHIRPS data, and it determined that the amount of annual rainfall had been reduced approximately in Iran since 2008. In this way, appropriate and new methods should apply in the management style of groundwater resources in the study area. However, reducing rainfall can reduce water storage levels significantly, but other factors, including the contribution of human resources, should be carefully discussed. Therefore, suggested that in subsequent studies, be considered the human contribution to the process of groundwater levels and water storage changes in the study area.

\section{REFERENCES}

Banerjee, C., and Kumar, D.N., 2018. Analyzing Large-Scale Hydrologic Processes Using GRACE and Hydrometeorological Datasets. Water resources management 32(13). doi.org/10.1007/s11269-018-2070-x.

Chen, J., Famiglietti, J.S., Scanlon, B.R., and Rodell, M., 2016. Remote Sensing and Water Resources, Springer. doi.org/10.1007/s10712-015-9332-4.

Doell, P., Mueller Schmied, H., Schuh, C., Portmann, F.T. and Eicker, A., 2014. Global-scale assessment of groundwater depletion and related groundwater abstractions: Combining hydrological modelling with information from good observations and GRACE satellites. Water Resources Research 50(7). doi.org/10.1002/ 2014WR015595.

Google Earth Engine. developers.google.com/earthengine/datasets/catalog/NASA_GRACE_MASS_GRIDS_LAN D.

Google Earth Engine. developers.google.com/earthengine/datasets/catalog/UCSB-CHG_CHIRPS_PENTAD. 
Funk, C., Peterson, P., Landsfeld, M., Pedreros, D., Verdin, J., Shukla, S., Husak, G., Rowland, J., Harrison, L. and Hoell, A., 2015 The climate hazards infrared precipitation with stationsa new environmental record for monitoring extremes. Scientific data 2, 150066. doi.org/ 10.1038/sdata.2015.66.

Joodaki, G., 2014. Earth mass change tracking using GRACE satellite gravity data. brage.bibsys.no/xmlui/handle/11250/232785.

Joodaki, G., Wahr, J. and Swenson, S., 2014. Estimating the human contribution to groundwater depletion in the Middle East, from GRACE data, land surface models, and well observations. Water Resources Research 50(3). doi.org/10.1002/2013WR014633.

Landerer, F.W., and Swenson, S., 2012. Accuracy of scaled GRACE terrestrial water storage estimates. Water Resources Research 48(4). doi.org/10.1029/2011WR011453.

I.R.OF IRAN Meteorological Organization. irimo.ir/eng/index.php.

Swenson, S. and Wahr, J., 2002. Methods for inferring regional surface-mass anomalies from Gravity Recovery and Climate Experiment (GRACE) measurements of time-variable gravity. Journal of Geophysical Research: Solid Earth 107(B9), ETG $3-$ 1-ETG 3-13. doi.org/10.1029/2001JB000576.

Swenson, S. and Wahr, J., 2006. Post-processing removal of correlated errors in GRACE data. Geophysical Research Letters 33(8). doi.org/10.1029/2005GL025285.

Swenson, S. and Wahr, J., 2009 Monitoring the water balance of Lake Victoria, East Africa, from space. Journal of Hydrology 370(1-4). doi.org/10.1016/j.jhydrol.2009.03.008.

Swenson, S., Yeh, P.J.F., Wahr, J. and Famiglietti, J., 2006. A comparison of terrestrial water storage variations from GRACE with in situ measurements from Illinois. Geophysical Research Letters 33(16). doi.org/10.1029/2006GL026962.

Voss, K.A., Famiglietti, J.S., Lo, M., De Linage, C., Rodell, M. and Swenson, S.C., 2013. Groundwater depletion in the Middle East from GRACE with implications for transboundary water management in the Tigris-Euphrates-Western Iran region. Water Resources Research 49(2). doi.org/10.1002/wrcr.20078.

Wahr, J., Swenson, S., Zlotnicki, V. and Velicogna, I., 2004. Time-variable gravity from GRACE: First results. Geophysical Research Letters 31(11). doi.org/10.1029/2004GL019779. 